\title{
Making the right real! : A case study on the implementation of the right to sport for persons with disabilities in Ethiopia
}

\section{Mojtahedi, Mina C.}

2018-08

Mojtahedi , M C \& Katsui , H 2018 , ' Making the right real! A case study on the implementation of the right to sport for persons with disabilities in Ethiopia ', Sport in Society , vol. 21 , no. 1 , pp. 40-49 . https://doi.org/10.1080/17430437.2016.1225898

http://hdl.handle.net/10138/234043

https://doi.org/10.1080/17430437.2016.1225898

acceptedVersion

Downloaded from Helda, University of Helsinki institutional repository.

This is an electronic reprint of the original article.

This reprint may differ from the original in pagination and typographic detail.

Please cite the original version. 


\title{
Making the right real! A case study on the implementation of the right to sport for persons with disabilities in Ethiopia
}

\author{
Mina C. Mojtahedi and Hisayo Katsui
}

Threshold Association, Helsinki, Finland and University of Helsinki, Finland; Abilis Foundation, Helsinki, Finland

\begin{abstract}
Even though the right to participate in sport, recreation and play is stipulated in the United Nations' Convention on the Rights of Persons with Disabilities as a stand-alone provision, it is often treated as a "second class right". This paper critically investigates challenges of realizing this right in the context of Ethiopia. Findings are based on wheelchair basketball trainings held in Ethiopia for persons with physical disabilities in 2015 as a case study and from follow-up data to assess the impact of the trainings. Firstly, inequalities in structures related to disability sports between the Global North and South are described. Secondly, examples of discrimination between groups within disability communities are shown. Lastly, the complex nature of realizing the rights of persons with disabilities is examined in the context of accessibility and sports. In conclusion, we summarize the key components for genuine implementation of 'Sports for All'.
\end{abstract}

In international development programmes sport is most often used as a tool for social benefit, such as empowerment (Kay, 2009; Wedgwood, 2014) and integration (Wilson and Khoo, 2013), for the realization of human rights through sports and for the realization of rights of specific groups such as women or persons with disabilities (Donnelly, 2008). There is a wide range of international programmes focused on sport as a tool for advancing social inclusion and empowering persons with disabilities. In fact, the United Nations Sport for Development and Peace International Working Group (2008) provides a broad set of recommendations to governments on how to use sport for development and what the benefits are to persons with disabilities. For example using sports as a communication platform to improve access by women with disabilities to health information and education (ibid.). Another example is reducing stigma associated with disability that prevents children with disabilities from attending school (ibid.).

However, access to and participation in sport is also a right in itself. One of the fundamental principles of the Olympic Charter (International Olympic Committee, 2015) is that the practice of sport is a human right. Several international conventions and declarations state the right to leisure, cultural life and sports, including, most importantly, the Universal Declaration of Human Rights (United Nations, 1948) in which is included the right to rest and leisure. The Convention on the Rights of Persons with Disabilities (CRPD) (United Nations, 2006) is a human rights convention with the purpose of 'promoting, protecting and ensuring the full and equal enjoyment of all human rights and fundamental freedoms by all persons with disabilities.' The CRPD Article 30 is a stand-alone article on the rights for persons and children with disabilities to participate on an equal basis in cultural life, recreation, leisure and sport.

\section{Barriers to making the right to sport real in the Global South}

Although persons with disabilities form $15 \%$ of the world's population and $80 \%$ of persons 
with disabilities live in the Global South (WHO and The World Bank 2011) persons with disabilities in the Global South have very few opportunities to do sport. The fact that the Sustainable Development Goals (SDGs) include 13 mentions on education in its goals and targets, while no mention is given to sports, implies that all rights are not equally paid attention to in reality today. Also the disabled activists' movement prioritizes equality in education, employment, health, housing and transportation and there is an apparent lack of interest in the right to sport for persons with disabilities (Braye, Dixon, and Gibbons 2013). 'The principle of 'progressive realization' recognizes that some rights may have to be given priority over others, because not all rights can be fulfilled at the same time or at the same place' (OHCHR 2006). 'Leaving no one behind' is a global slogan for the SDGs which pay great attention to human rights principles such as non-discrimination and equality.

However, there are many risks that persons with disabilities in the Global South will be, once again, left behind in the global discourse on human rights and development in general, and it seems that the right to participate in recreational activities and sports will receive very little attention.

Contradictory to the concept of 'Sport for All', many marginalized groups are excluded from this right. There are often sports opportunities for 'either able or disabled' (Carter et al. 2014) in the Global North, and thus one of the mainstream discourses on disability and sports today is to promote inclusive sports. When it comes to the right to sport of persons with disabilities in the Global South, it has not been paid sufficient attention to (Wilson and Khoo 2013), especially in comparison to other rights, such as the right to education. Also, as access of persons with disabilities to sports is severely limited in the Global South, provision of inclusive sport is not yet on the agenda in most countries. A study found that Kenyan wheelchair basketball players faced many challenges such as negative attitudes towards persons with disabilities, transportation, and lack of financial resources (Crawford and Stodolska 2008). Similarly, Malaysian athletes with disabilities faced attitudinal difficulties such as lack of commitment and poor understanding of disability among coaches, and also structural barriers such as inaccessible sports facilities, lack of adaptive sports equipment and lack of funding for disability sport (Wilson and Khoo 2013). Inclusive sports is far from a reality in many parts of the Global South where one of the first steps still would be to make efforts to secure access to sport for persons with disabilities.

The gap between disabled and non-disabled populations is growing in many sectors. For instance, while many governments of low-income countries, including Ethiopian, have succeeded in dramatically increasing the net enrolment rate in primary education to over $90 \%$ for both boys and girls over the last two decades, the progress observed with respect to children with disabilities is minimal (Katsui et al. 2014). In fact, in Ethiopia, 97\% of children with disabilities do not attend school (Ministry of Education of Ethiopia 2012). In the Global North, inclusion of children with disabilities into physical education activities within schools is one of the steps towards inclusive sports (Carter et al. 2014). In the Global South, however, most children with disabilities are not even in schools and thus miss the opportunity of sport altogether. When intersection of gender, age, ethnicity, religion and so forth is taken into account, root causes of inequalities including poverty and stigma are intertwined and multi-layered. Considering such inequalities exist in the education sector, 
which is often a primary focus of development efforts, and that the right to sport does not receive much attention, it is no wonder that very little information is available on the realization of the right of persons with disabilities living in the Global South to participate in recreational activities and sport.

\section{Access to sport in the Ethiopian context}

This paper elaborates on the right to sport for persons with disabilities in low-income countries, specifically in Ethiopia, using wheelchair basketball trainings held in 2015 as a case study. The following sections describe the trainings and follow-up data collection, the issues underlying the challenges to realizing the right to sport as well as access to sport of persons with disabilities and the benefits to persons with disabilities reported in this study.

Ethiopia has a long tradition of organized sport and in particular in basketball. The Ethiopian Basketball Federation has been a member of the International Basketball Federation (FIBA) since 1949. The Sport Policy of the Federal Democratic Republic of Ethiopia (1998) states under section 3 on 'Methods for the Execution of the Policy', that the government should 'ensure the participation of the disabled in sports activities at their locality, educational institutions and working places and to also ascertain their equal sharing of the benefits'. Regarding disability sports, the Ethiopian National Paralympic Committee is the primary organized disability sport representative. Ethiopian disabled athletics and power-lifting athletes have represented their country in the Paralympics in the 1960s and 1970s and then later, regularly since 2004. However, despite disability inclusion in the policy, the government does not provide subsidies for disability sports, as is the broad trend in Sub-Saharan Africa in general and thus preventing or slowing the development of organized disability sports (Novak 2014). Nor have policies been translated into practice to remove barriers, such as inaccessible facilities, lack of adaptive sports equipment, negative attitudes towards disability, and therefore access of persons with disabilities to sport continues to be very poor. Nevertheless, some efforts in wheelchair basketball in Ethiopia have been initiated, and in 2013 the Ethiopian Basketball Federation formed a wheelchair basketball committee with the purpose of developing and integrating wheelchair basketball into the federation's structure.

Although Ethiopia has non-disabled basketball leagues, a national basketball federation, and some organized disability sports, community-based recreational sports, ie sports where anybody can participate regardless of athletic status, is almost non-existent for persons with disabilities. That is, inclusive sport is largely not available or accessible for persons with disabilities in Ethiopia, as is often the case for countries in the Global South. Therefore, this paper focuses on access to sport rather than inclusive sport.

Wheelchair basketball is a new sport in Ethiopia. The national basketball federation lacks information on wheelchair basketball, lacks the adaptive equipment needed for the sport, and therefore has not previously provided access for persons with disabilities to this sport. The purpose of the training camps was to provide access to sport for persons with disabilities by increasing knowledge of the sport and providing basic adaptive sports equipment. 
The aim was to integrate wheelchair basketball into local basketball organizations and provide a foundation to support the establishment of community-based recreational wheelchair basketball teams that practise regularly and could form a wheelchair basketball league in the future.

\section{Methodology}

The fieldwork conducted in Ethiopia during 2015 is described in two parts: (1) wheelchair basketball training camps and (2) follow-up questionnaires to participants from the training camps. One of the researchers played the role of a coach for the wheelchair basketball camps. Seventy persons with physical disabilities (30 women and 40 men) participated in six wheelchair basketball training camps that were held in five regions in Ethiopia between March and May of 2015. Camps were organized with collaboration between an international humanitarian organization and government funded national and regional basketball organizations. Funding for camps and the sports equipment (e.g. wheelchairs) were provided as a donation from that international humanitarian organization.

Follow-up data from the different stakeholders of the camps were collected by the researchers through observation, informal communication, questionnaire and through emails with key informants after the camps. Questionnaires to participants were administered 7-9 months after the training camps. The questionnaire was presented to groups and translated to regional languages as needed. Participants were given as much time as they needed to answer each question. A transcriber was assigned to each illiterate participant. All completed questionnaires were translated from the local language into English. Findings through observation and informal communication were written down in a notebook. Data were compiled into an Excel data-set. Qualitative content analysis technique was used to identify key thematic areas.

Data were collected from 31 Ethiopians (44\% of camp participants, 11 women, 20 men). Data were not collected from all participants due to the following reasons: they could not be reached due to lack of access for security reasons; contact information was lacking; or participants were not interested in completing the questionnaire.

Ethical issues such as informed consent, voluntary participation, privacy and right to withdraw were paid scrupulous attention to due to the politically sensitive environment in Ethiopia. In order to avoid any unintended negative consequences and to secure confidentiality, the main findings summarized in the following section deliberately hide the information of the locations where the experiences took place.

Table 1 shows the main characteristics of the participants that responded to the questionnaires. Despite the near global eradication of polio, it is still quite prevalent in Ethiopia as can be seen from the prevalence of polio among the participants. There is also a high prevalence of amputees among the participants potentially due to many of the participants being veterans of Ethiopia's civil war that lasted until 1991. The level of education among participants was quite low, and the majority gain income through self- 
employment. This is representative of the general population of persons with disabilities in Ethiopia, as there are many barriers for persons with disabilities to access education and gain employment.

Table 1. Characteristics of the participants

\begin{tabular}{|l|r|}
\hline Number of respondents & \\
\hline Total & 31 \\
\hline Women & 11 \\
\hline Men & 20 \\
\hline Average age, years \pm standard deviation & $29.5 \pm 8.2$ \\
\hline Type/Cause of physical disability & 14 \\
\hline Polio & 10 \\
\hline Amputee & 2 \\
\hline Spina bifida & 1 \\
\hline Spina cord injury & 4 \\
\hline Other & \\
\hline Highest level of education & 4 \\
\hline No schooling & 12 \\
\hline Elementary & 7 \\
\hline Secondary & 2 \\
\hline High school & 3 \\
\hline Vocational training & 2 \\
\hline University & 1 \\
\hline Other & 2 \\
\hline Employment status & 16 \\
\hline Employed & 7 \\
\hline Self-employed & 2 \\
\hline Unemployed & 4 \\
\hline Student & 30 \\
\hline Other & 9 \\
\hline $\begin{array}{l}\text { Number of participants that were currently doing another } \\
\text { sport }\end{array}$ & 19 \\
\hline $\begin{array}{l}\text { Number of participants that had previously played in } \\
\text { wheelchair basketball before camps }\end{array}$ & \\
\hline $\begin{array}{l}\text { Number of participants that continued regular wheelchair } \\
\text { basketball training after camps }\end{array}$ & \\
\hline
\end{tabular}

Many of the camp participants had been affiliated to the organizers and played other sports and/or wheelchair basketball even before the camps.

Access to sports in general seemed quite high among the training camp participants. The typical sports that were reported were wheelchair racing, weight-lifting, table tennis and javelin. All sports were organized by local disability organizations, regional sports organizations and projects conducted by municipalities. It is likely that the athleticism of 
the participants caused recruitment bias, ie because participants were already involved in sports and interested in sports, they were more likely to register for a wheelchair basketball training camp. Also, they were more likely to be recruited or gained information about the training camps because they were already involved in organized sports and local disability organizations. Therefore, persons with disabilities not connected to disability organizations or sports organizations were to some extent excluded from the training camps because of this selection bias.

A limitation in this study is the missing qualitative information that voices the experience of the training camp participants. The community members' view is important in providing an authentic, in-depth perspective and also in avoiding colonization of research and data that 'over-reaches' (Kay 2009). Attempts were made to collect qualitative documentation on the impact of the training camps and the realization of the right to sport on persons with disabilities. However, qualitative data analysis was difficult because the data that were collected were limited. Also, continued training in the different regions was so sparse that assessing an impact on the lives of persons with disabilities could no longer be shown. Nevertheless, this study provides some insight into challenges for ensuring access of persons with disability to sport and progressing towards inclusive sport in the Global South.

\section{Main findings and discussion}

The primary outcome of the follow-up findings was that even ensuring basic provisions for disability sport was not enough to create sustainable access of persons with disabilities to sport. Regular training did not continue in the majority of the regions where wheelchair basketball training was held. Out of the total five regions from which training camp participants came, three regions had regular practices after the training camps. In one of these regions, wheelchair basketball training was already provided with the support from other donors prior to the training camps. Therefore, in actuality, wheelchair basketball was successfully introduced in only two regions out of five (40\%). The reasons for why access to sport and regular training was not sustained in the majority of the regions are discussed in this section.

In order for rights of persons with disabilities to be realized, more often than not, it requires that access be provided not just in terms of sport but also in several sectors. In other words, there are several pieces that must be in place at the same time to allow participation in sport for persons with disabilities. Access includes features such as availability, accessibility and affordability. In the present case study, data collected from the participants of the camps showed that inaccessibility of the built environment was the major barrier hindering the access of persons with disabilities to opportunities in sport. Inaccessibility had several implications: most sports facilities in the regions were not accessible to wheelchair users and persons with other physical impairments; the storage facilities where the sports wheelchairs were kept were not accessible to persons with physical disabilities and required a volunteer to bring the equipment. Affordability of adaptive equipment was not an issue, because equipment was donated in each region. However, in general, the high cost of adaptive equipment is a barrier and adaptive sports equipment is not available in Ethiopia and must be purchased from international companies. 
Participants raised affordability as a barrier in terms of cost for transportation to reach sports facilities with a better level of accessibility but which were far from participants' homes.

Ensuring access for persons with disabilities is the responsibility of the government, whether federal or regional. Getting all key pieces for provision of access in place at the same time is complex because different governmental bodies are responsible for providing access in different sectors. Public transportation is under the transport sector, sports facilities are often under the ministry of education or sport, roads and pavements are under the infrastructure or sometimes transport sector, assistive devices are under the health and social welfare sector. Disability inclusion must be integrated in all sectors so that it is possible for persons with disabilities to participate in society in general.

Novak describes how the need for adaptive and technology-based equipment and trained coaches who have knowledge of the disability sport creates a 'disability divide' between those who have access and those who do not have access to these resources (Novak 2014). This divide in disability sports is evident between affluent countries in the Global North and the low- and middle-income countries in the Global South. This can be seen for example in comparing the number of low-income countries and athletes from these countries participating in the Paralympics to those from wealthy countries. Novak further describes how disability sports movements in the Global South have primarily been a result of funding from development agencies or other donors from the Global North. For example, with the funding from Abilis Foundation in Finland, Mozambican persons with disabilities formed the Paralympic Committee of Mozambique and entered a Paralympic team to compete in the London 2012 Paralympics.

Novak's 'disability divide' in adaptive equipment and trained coaches was not preventing access to sport in this present case study. The adaptive equipment needed for practising wheelchair basketball, namely the wheelchairs, were donated to the local organizers. Also, the training camps included coaches' clinics in order to provide trained coaches to continue with regular training. Thus, the technical support was provided to ensure sustainability, but nevertheless, in most regions, the equipment was not put to use and coaches did not continue the work. However, international aid dependence was apparent in the present case study. The camps themselves were organized with funding from international donors after which the local organizers were expected to secure local, eg governmental funding, in order to continue. One reason for the disappointingly low success rate in continuing wheelchair basketball training was the lack of funds allocated by the local sports organizations to regular training after the camps, similar to previous findings in the Global South (Wilson and Khoo 2013). So, when the funding ended, so did the training. It is quite common that disability sports do not receive government subsidies in the Global South (Novak 2014) despite many governments' sport policies including articles supporting the inclusion of athletes with disabilities. Therefore, the underlying reason appears to be lack of commitment to disability sports and allocation of funds and discriminatory attitudes towards disability rather than the lack of funds itself. Disability sports are not seen as an equal right to non-disability sports.

An integral part of the CRPD is that persons with disabilities are not simply objects for 
which rights are realized, but rather that persons with disabilities are a part of all steps in the process of realizing rights (UN (United Nations) 2006). In other words, duty-bearers should consult with persons with disabilities in all issues regarding them. In Ethiopia legislation and policies include articles on participation in sports of persons with disabilities, but duty-bearers, in this case sports organizations, did not consult with persons with disabilities in these matters. Not even the Ethiopian Basketball Federation's wheelchair basketball committee included a person with a disability with knowledge of disability sports. So not only is the right to sport for persons with disabilities poorly implemented, the right of persons with disabilities to be heard and participate also in the planning steps is also not realized. Appointing highly motivated persons with disabilities in positions for implementing government policies on disability sport has resulted in successfully improving provisions for disability sports in several countries in the Global South (personal interview with a program officer at the United States Department of State division devoted to sports diplomacy, February 6, 2016).

In some regions there were discriminatory processes that account for the lack of continued regular training. Sport as a human right does not mean that it uniformly includes all groups. In fact, sport can promote discrimination, and often race, class and gender exclusion are maintained in sports (Donnelly 2008). In the present case three forms of discrimination took place. Within disability communities there exist hierarchical structures differentiating disability groups, such as between different forms of impairment (Deal 2003). In many war-torn countries, veterans have a special political status because they are seen as having sacrificed for their country, and government provides additional benefits to veterans, including veterans with disabilities. In the region where regular training was provided both before and after the camps, veterans with disabilities had almost exclusive access to the sports facility, to the sports wheelchairs, and a coach attended practices regularly. In another region, similar power structures prevented persons with disabilities living in the community from accessing the sports wheelchairs, which were owned by a local educational institution. The educational institution claimed that because the sports wheelchairs were donated specifically to them, they would allow only their own students to access the sports wheelchairs and not community members.

Gender inequality is highly prevalent in disability sports but poorly described in the literature. Women with disabilities have the right to the same opportunities as men with disabilities in access to regular training and advancing in sports to internationally competitive levels, but more often than not, this is not the case in the Global North. In wheelchair basketball this is evidenced by the very small number of teams for women compared with for men in most Western countries. There is a risk when introducing disability sports in the Global South that the same gender inequalities are replicated. In addition, women with disabilities often face double discrimination because of negative societal attitudes towards gender and disability in the Global South (Katsui and Mojtahedi 2015). Women with disabilities are often kept at home by their families practically as servants, and are denied their rights to participate in society (Katsui and Mojtahedi 2015). Gender discrimination was clearly apparent in the findings of this study. At the training camps, every effort was made to ensure gender equality. However, in one of the regions where wheelchair basketball training continued to be organized after the camp by a local 
disability organization, training was provided only for an all-male group. Women with disabilities were not given equal access to the trainings. On the other hand, a small but significant result was achieved in other regions where more women are now attending regular wheelchair basketball training than before in other regions. In two regions where mixed gender balance was achieved in the training camps and where training has continued, women form approximately half of the players in regular practices. This is a promising start, but the goal should be that women with disabilities have the opportunity to train with their peers rather than compete against men who, generally speaking, tend to be larger and stronger.

\section{Conclusion}

This paper provides insight to some of the challenges in realizing the right of persons with disability to sport and can be used to design programmes to address the problems persons with disabilities face in accessing sport. Resources such as information on wheelchair basketball, funding for training camps and sports wheelchairs were provided from non-local donors. In other words, the foundation for improving access of persons with disabilities to wheelchair basketball was laid. In order to progress towards inclusive sports, essential provisions that are routinely provided in non-disabled sports should be provided equally in disability sports. However, the low level of continuity after the input from donors indicates that duty-bearers are not realizing this particular right for persons with disabilities in the Global South. This supports the concept presented by Novak on dependency on international development funds. Importantly, the right to sport for persons with disabilities can only be realized when duty-bearers address disability rights and gender equality in all sectors to ensure access, such as accessibility of the built environment including sports facilities and transportation, and provision of affordable assistive devices including adapted sports equipment (Novak 2014).

However, positive and inclusive attitudes towards equality, disability and the right to sport can provide powerful motivation in the development of organized disability sport. The primary reasons why continued training was successful in three regions where training camps were held was the high level of commitment among the persons with disabilities to attend practices and of coaches to provide the necessary support. As an example, one of the regions, where regular wheelchair basketball practices have been organized since the training camp, is also one of the least accessible locations compared to the other regions. Although the sports organization which is responsible for providing sports in that particular region provides no financial or other form of support for wheelchair basketball practices, a dedicated basketball coach volunteers his time and runs practices for persons with disabilities when the court is available. In addition, he brings all the sports wheelchairs from the storage facility to the court because the players are not able to access the storage. This shows that a commitment to providing equal opportunities to persons with disabilities to participate in sport can to some extent overcome even the lack of financial and structural support. This positive example, albeit encouraging, is not sustainable without a serious commitment from duty-bearers to fulfil their role in realizing the rights of persons with disabilities in all governmental sectors. Further research is needed to address the more 
specific roles of duty-bearers and highlight the experiences of the rights-holders, persons with disabilities in access to sport in the Global South.

\section{Acknowledgements}

The authors would like to thank the International Committee of the Red Cross, Daniel Mekonnen, Rinor Gashi and the participants for their assistance in this project.

\section{Disclosure statement}

No potential conflict of interest was reported by the authors.

\section{References:}

Braye, S., K. Dixon, and T. Gibbons. 2013. “A Mockery of Equality’: An Exploratory Investigation into Disabled Activists' Views of the Paralympic Games.” Disability \& Society 28 (7): 984-996.

Carter, B. et al. 2014. "'Just kids playing sport (in a chair)': experiences of children, families and stakeholders attending a wheelchair sports club." Disability \& Society 29(6):938-952.

Crawford, J. L., and M. Stodolska. 2008. "Constraints Experienced by Elite Athletes with Disabilities in Kenya, with Implications for the Development of a New Hierarchical Model of Constraints at the Societal Level." Journal of Leisure Research 40 (1): 128155.

Deal, Mark. 2003. "Disabled people's attitudes toward other impairment groups: a hierarchy of impairments." Disability \& Society $18 \quad$ (7):897-910. doi: 10.1080/0968759032000127317.

Donnelly, Peter. 2008. "Sport and human rights." Sport in Society 11 (4):381-394. doi: $10.1080 / 17430430802019326$.

Federal Democratic Republic of, Ethiopia. 1998. Sport Policy of The Federal Democratic Republich of Ethiopia.

International Olympic Committee, IOC. 2015. Olympic Charter. edited by IOC International Olympic Committee: International Olympic Committee, IOC.

Katsui, et al. 2014. Reducing inequalities: A human rights-based approach in Finland's development cooperation with special focus on gender and disability. Institute for Human Rights. Turku.

Katsui, Hisayo, and Mina C. Mojtahedi. 2015. "Intersection of disability and gender: multilayered experiences of Ethiopian women with disabilities." Development in Practice 25 (4):563-573. doi: 10.1080/09614524.2015.1031085.

Kay, Tess. 2009. "Developing through sport: evidencing sport impacts on young people." Sport in Society 12 (9):1177-1191. doi: 10.1080/17430430903137837.

Ministry of Education of Ethiopia, Ethiopia. 2012. Special Needs/Inclusive Education Strategy.: Ministry of Education. 
Novak, A. 2014. "Disability Sport in Sub-Saharan Africa: From Economic Underdevelopment to Uneven Empowerment." Disability and the Global South 1 (1):44-63.

Office of the United Nations High Commissioner for Human Rights, OHCHR. 2006. "Frequently Asked Questions on a Human Rights-Based Approach to Development Cooperation. $\quad$. $\quad$ Accessed 3.10 .2014 . http://www.ohchr.org/Documents/Publications/FAQen.pdf.

SDP and IWG (Sport for Development and Peace International Working Group). 2008. "Sports and Persons with Disabilities: Fostering Inclusion and Well-being." In Harnessing the Power of Sport for Development and Peace: Recommendations to Governments, 167-200. Toronto: Right to Play.

United Nations, UN. 1948. Universal Declaration of Human Rights. edited by UN United Nations.

United Nations, UN. 2006. Convention on the Rights of Persons with Disabilities and its Optional Protocol. edited by UN United Nations.

Wedgwood, N. 2014. "Hahn versus Guttmann: Revisiting 'Sports and the Political Movement of Disabled Persons'." Disability and Society, 29 (1): 129-142.

World Health Organization and The World Bank, WHO. 2011. World Report on Disability: World Health Organization.

Wilson, N.C. and Khoo, S. 2013. Benefits and barriers to sports participation for athletes with disabilities: the case of Malaysia. Disability and Society 28(8):1132-1145. 